\title{
dibaxu, de Juan Gelman: diáspora de la poesía en las galaxias de la transcreación
}

\section{Juan Gelman's dibaxu: Diaspora of Poetry in the Galaxies of Transcreation}

\author{
Susana Romano Sued \\ Universidad Nacional de Córdoba-Conicet \\ susana.romano@gmail.com
}

\section{Resumen}

dibaxu es un poemario "bilingüe" que consta de 29 textos en idioma ladino, o judezmo, o sefardí, de la poeta Franco-bosnia Clarisse Nicoïsky, vertidos al castellano por Juan Gelman. Con Haroldo de Campos considero que la traducción de Gelman es "transcreación”, que es como ha re-nombrado a la traducción literaria. Tanto los poemas originales como la transcreación de Gelman son en realidad un ars poetica, y ambos tienen lugar en la diáspora. Aquí se produce un encuentro entre Ética y Poética.

Palabras clave: diáspora, poesía, galaxias, transcreación, sefardí.

\begin{abstract}
dibaxu is bilingual poetry book consisting of 29 poems written in Ladino, Sephardi Hebrew, or Judaeo-Spanish by Clarisse Nicoïsky, a Franco-Bosnian poet translated by Juan Gelman into Spanish. Together with Haroldo de Campos I consider Gelman's translation as transcreation, the way Haroldo de Campos renamed the translation of literature. Both the original poems and Gelman's transcreation are actually an ars poetica, and both take place in the diaspora. Here occurs an encounter between Ethics and Poetics.
\end{abstract}

Keywords: Diaspora, Poetry, Galaxies, Transcreation, Sephardic. 
dibaxu comienza con la siguiente dedicatoria:

Para Aurora Bernárdez, quien además me introdujo en la poesía de Clarisse Nikoïidski, diáfana como un fuego. (Juan Gelman, dibaxu, 1994, pág. 13)

Los epígrafes, según se conoce en los glosarios de la teoría literaria, son "paratextos". El poemario cuyo título traducido del ladino significa "debajo" trae este primer texto, que está "delante", o "arriba" de todo el poemario. Aurora Bernárdez, ella misma interpres, aduanera y atesoradora de las memorias de la literatura a través de su eminente labor de traductora, justamente, como lo dice el epígrafe, fue quien introdujo a Gelman en el universo poético de la poeta de Bosnia Clarisse Nicoiidsky ${ }^{1}$, cuya lengua materna era el sefardí, y que ella readoptó para escribir poesía. Lengua materna reencontrada, y adoptada por el poeta cuya lengua paterna de origen es el yiddish.

En tiempos de su estancia forzosa en Francia, durante la cual trabajaba como traductor de la Unesco, Gelman emprendió su travesía por ese idioma ladino, en consonancia con su propia tradición de aduanero, de sujeto translaticio, frecuentador de lenguas e invenciones de transferencias idiomáticas. Una práctica de ajenidad, ostranenie $^{2}$, que introduce la figura paradójica de la mismidad que se recorta de lo extraño. Lo propio de la subjetividad está atravesado por la lengua del otro, materna y paterna, de los padres consanguíneos y de los que inscriben en la comunidad como marca identitaria. La grafía hebrea, en la que se escriben el ladino y el yidish, a la vez que extraña al castellano y al idioma dialectal germánico-eslavo, los convierte en una cantera universal de conservación de memorias. La poiesis y la techné permiten la labor de indicar, a veces de manera enigmática, lo solapado, lo que está debajo, lo que está más acá y más allá del propio texto.

El sefardí o sefardita, el ladino o judezmo, nombres para la lengua atesorada, es el alojo que ha elegido el poeta, no solamente en este libro, no solamente para el

1 Clarisse Nicoïdski (1938-1996) nació en Lyon en el seno de una familia judía inmigrada de Bosnia (Sarajevo). En un viaje que realiza en 1955 a África del Norte descubre Marrruecos. Casada con el pintor Robert Nicoïdski, y hermana del pintor Jacques Abinoun, tuvo una trayectoria continuada en la literatura, como crítica de arte, como biógrafa, y como libretista de ópera y sobre todo como novelista: escribió 15 novelas, y fue traducida a varias lenguas. Sus novelas, todas en lengua francesa, y con la excepción de unos pocos poemas en un periódico, la única colección de poesía publicada en vida fue Lus ojus, las manus, la boca, en Ladino. Nicoïdski aprendió el Sefardí de niña, cuando estuvo oculta con su familia en Lyon durante la ocupación Nazi durante el gobierno de Vichy.Unos años después del fin de la segunda guerra, se trasladó con sus padres a Casablanca, Marruecos, donde vivió desde 1954 hasta 1959. Su decisión de retornar a los sonidos de su infancia escribiendo en la lengua de sus padres y abuelos, su 'el spaniol muestro, fue desencadenada por la muerte de su madre. Y así comenzó a escribir un poema por cada una de sus novelas. Esos textos le fueron entregados a Gelman por Aurora Bernárdez, y entonces fue que comenzó su exploración ética por esa lengua. (Balbuena, 2009)(mi traducción)

2 Término consagrado por los formalistas rusos, se refiere al proceso por el cual el poeta torna extraños los vocablos, la lengua, con lo cual no solamente los desplaza de su contexto ordinario resituándolos en un marco artístico, sino que con ello despierta la simpraxis multiceptiva de la vida misma, una enargueia, una vivacidad de lo que es dicho enfilada hacia la experiencia compartida y repartida de aiesthesis poética. Con ello se desafía lo supuestamente autónomo del arte y se recupera la dimensión de la referencia o heteronomía. Aquí la dimensión metapoética cobra toda su relevancia. (cfr. Romano Sued, 2011) 
mundo de la poesía sino como una ética del vivir y del pensar. Lo hace aquí para hablar lo no dicho, para interrumpir la transparencia del español corriente, lengua dominante y expulsadora. Una diáspora interna, un insilio, constituyen el lecho, el yacimiento que provee al poeta su acervo para decir las memorias, aquellas cuya ajenidad se vuelve propia y universal al revelarse como una ética ${ }^{3}$.

La metapoética, dimensión principal de dibaxu, está en sintonía con la tradición de heteroglosia gelmaniana, su recurso a culturas encriptadas y vivas al mismo tiempo, lo cual constituye una clave importante del descifrado de su escritura; en este poemario bilingüe, mediante su puesta en escena de traductor imaginario e imaginado, según le conocemos en su largo trayecto de poeta, se manifiesta una teoría de la escritura. Esta, que como hemos mencionado es una variante del español medieval empleada por la comunidad judía, es colocada en dibaxu en cada poema en contigüidad especular junto al castellano actual, labor afirmativa y desmentidora a un tiempo: la transcreación ${ }^{4}$ se desenvuelve en un locus inconmensurable, una galaxia poética, donde lo que se refleja, especula con la atención requerida al lector, quien ha de acompañar al poeta en su diáspora, en su rol de visitador de esa lengua, ajena y propia. El destino se revela en la abertura hacia el antro, en lo que el indicio del signo pone en lo dicho que direcciona hacia lo que vendrá. Es lo entrevisto, es la destitución de la transparencia, cuyo andrajo cae, hacia abajo, debajo de lo que se ve.

dibaxu fue publicado en 1994; el prólogo que el autor llama "escolio", segundo paratexto, explica la circunstancia de su elección, y prepara a los lectores para un recorrido por el tiempo y por la peripecia del lenguaje. Me interesa en especial destacar, como he anticipado, la dimensión metapoética que, predicha en los poemas ladinos de Clarisse, se acentúan en las versiones de Gelman, sobre la que nos advierte en su prólogo: "Quizás este libro apenas sea una reflexión sobre el lenguaje desde su lugar más calcinado, la poesía” (7).

dibaxu contiene 29 poemas: en las páginas pares van los poemas en ladino y en las impares su repetición en castellano, lo que provoca una remisión recíproca de los textos exasperando la página convencional, dado que la función especular propia de las ediciones de poesía bilingüe, en el caso del empleo de un idioma "antepasado" que se traduce a sí mismo, obliga a un juego de superficies/topoi: lo que está enfrente, está debajo, lo que está al lado está sobre, y sucesivas combinaciones posibles que abren la lectura de este experimento en que el deíctico reposa sobre la extraneidad.

3 Cfr. http://www.expoesia.com/media/Ponencia_Bradford.pdf

4 Para el poeta y traductor brasileño Haroldo de Campos, la traducción poética es siempre una re-escritura creativa, una creación paralela cuyo carácter es productivo y reproductivo al mismo tiempo: se deriva de un texto previo en otra lengua y cultura y se introduce en el universo vernáculo otro de la lengua anfitriona. Partiendo por una parte de las postulaciones sobre el texto poético enunciadas por el teórico y poeta concretista alemán Max Bense acerca del carácter informatico de la textualidad poética, y de la definición jakobsoniana de traducción como transposición creativa, De Campos construye el concepto de "transcreación": no sólo el contenido es objeto de la acción translaticia, sino que indispensablemente se trasladan la fisicalidad y la materialidad de la palabra, es decir sus propiedades sonoras e icónicas. Cfr. De Campos (1996), Romano Sued (2007, 2009). 
Lo entrevisto, luego, es el ámbito que se anuncia, un advenir a la meta, y a lo meta, donde se entrebesca la materia prima del poema con los mundos: disposición en la página, cuartetas en las cuales varios de los versos son marcados con la barra oblicua (recurso prosódico y gráfico constante en el poetizar gelmaniano), y un continuo tú-vos, y tu adjetivo posesivo, reponiendo la conversación con la poesía misma. Entiendo que el tipo de metatextualidad poética que aquí se nos ofrece es el de la variante metapoética cultural, pues contiene la cuestión y la pregunta fundamentales acerca de la inscripción de la obra de arte en su época. La confrontación con pre-textos ya no es sólo una cuestión técnica sino cultural, cuando los diferentes procedimientos, así como las diferentes funciones de los procedimientos, tienen que ver con distintas visiones de mundo (Romano Sued,15).

La atención puesta entonces en el tejido de las continuas referencias a la dimensión poética nos hace reconocer un movimiento de caída que, lejos de que pudiera asociarse con la caída cristiana, remite al campo topológico: de Allí, debajo, en el inframundo del horror del exterminio, tras su descenso, catábasis poética, la palabra se recrea para llevar más lejos la ruptura de lenguaje propia de la escritura, hasta radicalizarla en el orden de lo entrevisto -como cuando se levanta la esquina de un manto para dejar asomar otra cosa- al cabo de su anábasis, recobro ético de las voces silenciadas 5 .

El recorrido poético se alza en vuelo, pues hay el desplazamiento metafórico y metonímico al vuelo del pájaro, figura que carga consigo el discurrir poético: de los labios a decir, de los labios al temblar y al oir, mudanza del tiempo y mudez, caída y quietud, del sueño al dormir y al pensar. El movimiento temporal activa y petrifica la memoria, pues coloca el pasado en la casa del tiempo, que es anáfora y ánfora, y a la vez da alas al movimiento danzante.

Gelman ha dejado el título intacto en su versión, lo cual nos pone de entrada en alerta sobre lo que ha de ser su cincelado del castellano para traer dibaxu a nuestra lengua.

Dice el primer poema ${ }^{6}$ :

el temblor de mis labios/

quiero decir: el temblor de mis besos

se oirá en tu pasado

conmigo en tu vino/

abriendo la puerta del tiempo/

tu sueño

5 Cfr. Romano Sued, 2007, “Deíctico, extraneidad, escritura” en www.expoesía.com/9-9

6 Il batideru di mis bezus/-quero dizer: il batideru di mis bezus-si sintirá in tu pasadu cun mí in tu vinu/-- avrindo la puarta dil tiempo/-tu sueniu-dexa cayer yuvia durmida/-dámila tu yuvia-mi quedarí/quietu-in tu yuvia di sueniu/lodnji nil pinser/sin spantu/sin sulvidu/-nila caza dil tiempo-sta il pasadu/dibaxu di tu piede/qui baila (Gelman8). 
deja caer lluvia dormida/

dame tu lluvia/

me detendré / quieto

en tu lluvia de sueño/

lejos en el pensar/

sin temor/sin olvido/

en la casa del tiempo

está el pasado/

debajo de tu pie/

que baila/

Obsérvese que aquí Gelman ha restituido disposición, grafía, rima asonante al explorar el castellano en sus posibilidades. Ha cambiado en ello "spantu", por "miedo", (cuarto verso de la segunda estrofa) si bien en el siguiente poema ha optado por la literalidad:

II

¿dónde está la llave de tu corazón?/

el pájaro que pasó es malo/

a mí no me dijo nada/

a mí me dejó temblando/

¿dónde está tu corazón ahora?

un árbol de espanto baila/ ${ }^{7}$

no tengo más que ojos con hambre

$\mathrm{y}$ un jarro sin agua/

debajo del canto está la voz/

debajo de la voz está la hoja

que el árbol dejó

caer de mi boca/

Las rimas asonantes reflejan y refractan el texto ladino, como $e-o, a-o i$ - $a$, entre otras, lo mismo que la repetición anafórica de sustantivos, verbos, por ejemplo: tiempo, pasado, temblor, temor, y pájaro-s, los cuales atraviesan el poemario, en su movimiento de

$7 \quad$..un árvuli di spantu balia (ibid, 10, verso 6). 
caída. El árbol que deja caer su hoja metaforiza el recorrido de la escritura, un canto hecho de voz y de hoja, de planta y de libro, ambas cayendo y cantando de la rama hacia la voz, hacia la boca y hacia vos.

El pájaro -los pájaros, el espanto (del pensar, opuesto al cantar), la voz, el corazón y el caer trazan un pentágono que atraviesa los tiempos, los polos, un meridiano topológico a la Paul Celan, re-torcido por la imposibilidad de caer hacia arriba, que precede a un vocativo que espera de un tú, duplicador del yo poético, que resulta en una teoría amorosa del poema. Reproduzco a continuación extractos de poemas y algún poema completo, en los que el diseño del Ars poética, pura metapoesía, se asoma, debajo de la denotación, potenciando la función poética ${ }^{8}$ :

III

...la mañana hace brillar a los pájaros/...

...la beberemos junto

con el espanto del pensar/

..calienta lo pasado/

di besos y los besos y los besos despertarán/

caeremos cerca del sol/...9

IV

el pájaro- que vuela en $\mathrm{mi} \mathrm{voz} /$-tan chico/-- por el pájaro pasa un camino-que va a tus ojos/-espera tu mano/-....el pájaro/la voz... ${ }^{10}$

VI

......hojas secas,/hojas frescas/-caen de tu voz/--dormidas

...mira cómo esperan-que el espanto se apague/--

el sol oye caer-tus hojas/ ${ }^{11}$

8 Señalo que cuando se trata de fragmentos las barras oblicuas corresponden a la grafía de los versos, en tanto el guión horizontal simple lo empleo como indicación de final de verso y el doble guión como final de estrofa y comienzo de otra.

9 Gelman, 1994, poema III: 14

10 Ibid poema IV: 15

11 Ibid, poema VI: 19 
VII

...se despertó la lluvia-de un pájaro- que espera al mar-en el mar/ ${ }^{12}$

IX

tu pie tiene hierba debajo

y una sombra donde escribe

el mar del vacío/..

la muerte nada sabe de vos/

tu pie tiene hierba debajo

y una sombra donde escribe

el mar del vacío/ ${ }^{13}$

$\mathrm{X}$

dices palabras con árboles/-tienen hojas que cantan- y pájaros-que juntan sol/-- tu silencio-despierta-los gritos-del mundo/ ${ }^{14}$

$\mathrm{XI}$

--en tu voz-el mar cae...15

XII

lo que me diste-es palabra que tiembla- en la mano del tiempo... ${ }^{16}$

XIII

eres

12 Ibid, poema VII: 21

13 Ibid, poema IX: 25

14 Ibid, poema X: 27

15 Ibid, poema XI: 29

16 Ibid, poema XII: 31 
mi única palabra/

no sé

tu nombre/ ${ }^{17}$

XIV

lo que hablas-deja caer-un pájaro-y le soy nido/--el pájaro calla... ${ }^{18}$

XV

tu voz está oscura... ${ }^{19}$

XVI

cuando esté muerto

oiré todavía

el temblor

de tu saya en el viento/

alguien que leyó estos versos

preguntó:"`¿cómo así?।

¿qué oirás? ¿qué temblor?/

¿qué saya?/¿qué viento?

le dije que callara/

que se sentara a mi mesa/

que bebiera mi vino/

que escribiera estos versos:

"cuando esté muerto

oiré todavía

el temblor

de tu saya en el viento" $/ 20$

17 Ibid, poema XIII: 33 (completo)

18 Ibid, poema XIV: 35

19 Ibid, poema XV: 37

20 Ibid, poema XVI: 39 


\section{XVIII}

todo lo que llaman tierra

es tiempo/

es espera en $\operatorname{vos} /{ }^{21}$

XX

..lo amado crea lo que se amará/-como tú/llave/-temblando-en la puerta del tiempo/22

\section{XXI}

oí tu voz en mi ventana/

mi ventana no da a tu voz/

apenas si da al mundo/

¿cómo vino tu voz?/

un pájaro nevado

come trigo

en el murmullo

del sol/23

\section{XXII}

...en el trigo de tu vientre-vuelan pájaros-que cantan-en lo que va a venir/24

\section{XXIV}

amarte es esto:

una palabra que está por decir/

un arbolito sin hojas

que da sombra/25

21 Ibid, poema XVIII: 43

22 Ibid. Poema XX: 47. Aquí Gelman traduce el vos del original en tú, "comu vos/yave/", a diferencia de otros versos en que conserva la literalidad, vgr. poema IX

23 Ibid, poema XXI: 49

24 Ibid, poema XXII: 51

25 Ibid, poema XXIV: 55 


\section{XXVI}

...ahora pienso-que un pajarito en tu voz-arrastra-la casa del otoño/26

\section{XXVIII}

...río de pena/-lloro de alegría/-¿qué palabra te dirá?/-¿qué nombre te nombrará? ${ }^{27}$ $\mathrm{Y}$ el poema final, que transcribo completo, cierra y abre al mismo tiempo el arte poética, que se alza desde abajo y roza en las repeticiones el primero y enlaza los restantes, como una falsa corona:

\section{XIX}

no están muertos los pájaros

de nuestros besos/

están muertos los besos/

los pájaros vuelan en el verde olvidar/

pondré mi espanto lejos/

debajo del pasado/

que arde

callado como el sol/

Como puede apreciarse a todo lo largo del poemario, la voz poética establece y restablece una voz lírica que se asienta en los ciclos vitales de todos los reinos, especialmente el vegetal, animado por el verbo de la poesía, que vive más allá de la frontera idiomática, geográfica e histórica. La articulación de lo que podría nombrarse como pasaje en el sentido benjaminiano, como ligazón de ruinas, que soporta la carga de una lengua desaparecida, y se hace cargo de la cultura de la desaparición, abordada continuamente desde los mútliples géneros que frecuenta Gelman.

En este aspecto, la homología que puede trazarse con la poética de Paul Celan, creador del "celaniano", y explorador de los límites de la lengua en perpetua diáspora en travesía de umbrales, es una muestra de la universalidad de los valores éticos que pueblan las galaxias de la memoria. Sobre todo la homología puede constatarse con el poemario que precisamente se titula Von Schwelle zu Schwelle (de umbral en umbral) 
Un señalamiento ético que propone traducir, hacer llegar en la lengua de todos, el amor por lo más propio de la comunidad, el legado de tradiciones que arrastra el idioma, lo que está hablando con voz inaudible, o en voces encriptadas (así se adjetiva también al idioma ladino) que requieren del tránsito de umbral para hacer escuchar.

Esta travesía diaspórica de Gelman refuta el estereotipo que confina su poesía entre los muros del coloquialismo social, de géneros de exilio en el sentido de la persecución política. La referencia directa que podría esperarse de los poemas a una "realidad" acuciante de horror, se escabulle en el delicado ritmo de la lengua arcaizada, se asoma como restos de otras dicciones, cual palimpsesto textual, y metapoetiza a la vez su propia regla de construcción.

En ese sentido, es también multidimensional el gesto de Gelman en el horizonte poético argentino y en habla hispana en general, por cuanto provoca una ruptura de tradiciones, por la vía de recurrir a la rémora de una lengua, rémora tomada principalmente en el sentido del rememorar benjaminiano. Y por el hecho de incorporar el proceso de la traducción en el centro mismo de la dimensión simbólica de la poesía. Diáspora, rapsodia, parodias. El poeta, se prueba nuevamente aquí, es un sismógrafo, como lo señalaba Hugo von Hoffmanstahl, al señalar la cualidad de anticipación del poeta ante el acontecimiento del mundo.

\section{Referencias}

Balbuena, Monique. “dibaxu: A Comparative Analysis of Clarisse Nicoïdski’s and Juan Gelman's Bilingual Poetry”. Romance Studies, Vol. 27 No. 4 (2009) 283297. Medio impreso.

Benjamin, Walter. "Die Aufgabe des Übersetzers", Gesammelte Schriften. Suhrkamp, 1972 , vol. 4, I, 9-21. Medio impreso.

Bradford, Lisa. http://www.expoesia.com/media/Ponencia_Bradford.pdf. 2010. Sitio web. De Campos, Haroldo. "A Transcriação do 'Lance de Dados' de Mallarmé”. Limites da traduzibilidade. Costa, L.A. (Org.). Salvador: EDUFBA, 1996. 29-40. Medio impreso.

Gelman, Juan. dibaxu. Buenos Aires: Espasa Calpe/Seix Barral, 1994. Medio impreso.

Romano Sued. Consuelo de Lenguaje. Problemáticas de Traducción, Córdoba: Alción, 2007. Medio impreso.

---."Deíctico, extraneidad, escritura: dibaxu, de Juan Gelman”. www.expoesía.com/. 9 - 9. 2007. Sitio web.

---."Metapoéticas". Metapoéticas de Literatura Argentina. Romano Sued, S. /Vera Barros, T. Córdoba: Epoké/El Emporio, 2011. Medio impreso. 